\title{
Influence of Sedation on Patients' Perceptions and Recovery in Patients Undergoing Minor Perianal Procedures under Spinal Saddle Block
}

\author{
Marc D. Schmittner ${ }^{a} \quad$ Christoph Janke ${ }^{a} \quad$ Marc E. Limmer $^{a} \quad$ Christel Weiss $^{b}$ \\ Dieter G. Bussen ${ }^{c}$ Grietje C. Beck ${ }^{a}$ \\ Departments of a Anaesthesiology and Critical Care Medicine and ${ }^{\mathrm{b}}$ Medical Statistics, University Medical Centre \\ Mannheim, and ${ }^{\mathrm{C} C e n t r e ~ o f ~ C o l o p r o c t o l o g y ~ M a n n h e i m, ~ M a n n h e i m, ~ G e r m a n y ~}$
}

\section{Key Words}

Sedation · Perianal surgery $\cdot$ Spinal anaesthesia $\cdot$ Saddle block

\begin{abstract}
Objectives: Additional intra-operative sedation may help improve acceptability and comfort of anaesthesia in patients undergoing minor anorectal (perianal) procedures under spinal saddle block. This observational study was done to determine which patients request sedatives and to what extent sedatives affect the patients' recovery. Subjects and Methods: During a 6-month period, 500 patients undergoing minor perianal procedures received $1.0 \mathrm{ml}$ hyperbaric bupivacaine $(0.5 \%)$. On request, a light sedation with propofol in bolus application was provided. Patients were evaluated postoperatively using a standardized questionnaire about their perceptions before, during and $48 \mathrm{~h}$ after the administration of anaesthesia. Results: More female (91/143, $63.6 \%)$ than male $(136 / 259,52.5 \%)$ patients $(p=0.0312)$ received sedation. Patients with sedation were significantly younger ( $46.7 \pm 13.8$ vs. $50 \pm 13.8$ years, $p=0.0171)$ and had a lower body mass index (BMl; $25.6 \pm 4.3$ vs. $27.5 \pm 5.1, p<$ $0.0001)$. Time to mobilization and first micturition was sig-
\end{abstract}

nificantly longer in patients with sedation ( 4.8 vs. $4.4 \mathrm{~h}, \mathrm{p}=$ 0.0194 and 5.8 vs. $5.4 \mathrm{~h}, \mathrm{p}=0.0188)$, which was associated with a higher incidence of nausea (7.5 vs. $1.7 \%, p=0.0083$ ). Conclusions: Female gender, younger age, lower body weight and lower BMI were associated with higher subjective requirements for sedation. The use of sedation showed prolongation of time to first mobilization and micturition and a higher incidence of nausea.

Copyright $\odot 2009$ S. Karger AG, Base

\section{Introduction}

Benign anorectal diseases are rather common in Western countries [1]. Besides general, local and epidural anaesthesia, spinal anaesthesia is a common method for minor perianal procedures [2-4]. 'Saddle block' describes spinal anaesthesia with a low dose of hyperbaric local anaesthetics where the parts of a patient's body that would touch a saddle are anaesthetized. Application of low-dose heavy bupivacaine ensures not only an early onset of a sensory block within a short time, but also long-lasting postoperative analgesia [5, 6]. Patients can receive intraoperative sedation not only to supplement regional an-

\section{KARGER}

Fax +41613061234

E-Mail karger@karger.ch

www.karger.com
(C) 2009 S. Karger AG, Basel

$1011-7571 / 10 / 0191-0051 \$ 26.00 / 0$

Accessible online at:

www.karger.com/mpp
Marc D. Schmittner, MD

Department of Anaesthesiology and Critical Care Medicine, University Hospital Mannheim, Theodor-Kutzer-Ufer 1-3, DE-68167 Mannheim (Germany) Tel. +49621383 2415, Fax +496213832164

E-Mail marc.schmittner@anaes.ma.uni-heidelberg.de 
aesthesia, but also to improve patient acceptability and reduce stress and anxiety. However, it can also cause cardiorespiratory complications [7-9]. Due to its rapid recovery profile, propofol is commonly used for sedation during regional anaesthesia [7-9]. While the substance has a positive impact on postoperative nausea and vomiting (PONV), it can also cause cardiorespiratory complications $[7,10]$. Patient satisfaction with sedation in general has already been investigated widely and has been found to be very high $[7,11]$.

Regional anaesthesia and analgesia have been shown to improve clinically oriented outcomes [12] and an increasing number of studies have incorporated patient satisfaction measurements. Most of the studies are focused on outcomes concerning analgesia, health-related quality of life, quality of postoperative recovery and patient satisfaction [12]. A major criticism is based on the methodology, since patient satisfaction is multidimensional, complex and not easy to measure [11]. Currently, although much investigation has been done on this topic, still no validated instrument to assess the effect of analgesic techniques on patient-reported outcomes in the perioperative period exists [12]. In this survey, we investigated in context the clinical data and subjective perceptions before, during and after the administration of saddle block anaesthesia in patients with and without sedation.

\section{Subjects and Methods}

This prospective, single-centre observational trial was performed according to the guidelines of the local institutional review board (Ethic Commission II, Faculty of Clinical Medicine Mannheim, Germany, vote: 2007-236N-MA). From February until July 2007, 674 patients received several in-house perianal procedures in the University Hospital Mannheim (table 1). Prior to the scheduled operation, all patients were interviewed by an anaesthesiologist and informed verbally and in writing about the study before consenting to participate. Patients who had a repeat anorectal surgery were excluded from this evaluation, as were individuals with mental diseases or language barriers. One hundred and seventy-four patients did not meet the inclusion criteria (117 declined to participate in the study; 48 had a language barrier; 9 had repeat surgery). Informed written consent was obtained from 500 adult patients (ASA status I-III) who underwent minor perianal procedures (table 1) using the saddle block technique. According to the guidelines of our local Institutional Review Board (Ethic Commission II, Faculty of Clinical Medicine Mannheim, Germany), all patients also received a standardized questionnaire with the request to complete it on a voluntary basis. The questionnaire was designed to elicit patients' most frequently verbalized experiences and problems before, during and after saddle block anaesthesia. Patients were first asked to provide demographic data and state their knowledge of 'spinal anaesthesia' in general. To re-
Table 1. Diagnoses of all 500 responding patients

\begin{tabular}{lc}
\hline Diagnosis & Cases \\
\hline Fistula & $233(46.6)$ \\
Haemorrhoids & $143(28.6)$ \\
Chronic fissures & $64(12.8)$ \\
Tumour & $13(2.6)$ \\
Condyloma & $9(1.8)$ \\
Acne inversa & $6(1.2)$ \\
Abscesses & $5(1.0)$ \\
Other & $27(5.4)$ \\
\hline
\end{tabular}

Figures in parentheses are percentages.

duce bias, the survey had to be answered before the first contact with the anaesthesiologist in the hospital when the anaesthesia technique was explained. Second, patients were asked about their subjective experiences during the performance of spinal anaesthesia and the operation, side effects, duration of block and an evaluation of the efficacy of saddle block anaesthesia. The questionnaires were handed out directly after the administration of spinal anaesthesia and collected $48 \mathrm{~h}$ after surgery. Information about side effects was also reported on a separate questionnaire administered by the performing anaesthesiologist.

Anaesthesia and sedation were performed by staff grade anaesthesiologists only who were members of the study group. According to the current guidelines for preoperative nil per os, patients were allowed to drink small amounts of clear liquids until $2 \mathrm{~h}$ before the administration of anaesthesia. Vital parameters, ECG, blood pressure and $\mathrm{SO}_{2}$ were continuously measured during the procedure. Patients received an infusion with a maximum of $500 \mathrm{ml}$ crystalloid solution (Deltajonin; Delta Select, Dreieich, Germany) via a 20 -gauge peripheral vein needle (Liniest Purr; Klinika Medical, Singen, Germany). All patients received a spinal saddle block with $1.0 \mathrm{ml}$ hyperbaric bupivacaine $0.5 \%$ (Bucain $0.5 \%$ hyperbar; Delta Select) via a 25 -gauge Whitacre pencil point needle (BD Whitacre Needle; Becton Dickinson, Madrid, Spain) which was introduced at L4/5 interspace in a sitting position. In case of bradycardia ( $<50$ beats per min), $0.5 \mathrm{mg}$ atropine (Eifelfango, Bad Neuenahr, Germany) was applied. If the systolic blood pressure decreased to lower than $80 \mathrm{~mm} \mathrm{Hg}$ or was lower than $20 \%$ of its basic value, $1.0 \mathrm{ml}$ of the composite consisting of cafedrine and theodrenaline (Akrinor; AWD Pharma, Dresden, Germany) was injected intravenously. Simultaneously, $200 \mathrm{ml}$ crystalloid solution was supplemented. All patients were left in the sitting position for $20 \mathrm{~min}$, a fixation period, after which the anaesthesiologist tested the sensory block. With a long surgical toothless clamp, the block was gently applied radially, starting from the anal orifice, in different diagonal directions until satisfactory block had reached segment S4. In case of an insufficient sensory block, the patient received general anaesthesia and was excluded from the study. The patients were then transferred into the operating theatre where the surgery was performed in lithotomy position. On demand, additional sedation with propofol (propofol 1\%; Fresenius Kabi, Bad Homburg, Germany) was performed in bolus application until a light sedation was reached, in 
Table 2. Demographic data of the respondents

\begin{tabular}{lcccc}
\hline Demographic data & $\begin{array}{l}\text { Responding patients } \\
(\mathrm{n}=402 ; 100 \%)\end{array}$ & $\begin{array}{l}\text { With sedation } \\
(\mathrm{n}=227 ; 56.5 \%)\end{array}$ & $\begin{array}{l}\text { Without sedation } \\
(\mathrm{n}=175 ; 43.5 \%)\end{array}$ & p value \\
\hline Women & $143(35.6)$ & $91 / 143(63.6)$ & $52 / 143(36.4)$ & $0.0312^{*}$ \\
Men & $259(64.4)$ & $136 / 259(52.5)$ & $123 / 259(47.5)$ & $0.0171^{*}$ \\
Age, years & $48.2 \pm 13.9$ & $46.7 \pm 13.8$ & $50 \pm 13.8$ & 0.1004 \\
Height, cm & $173.7 \pm 9.2$ & $173.1 \pm 9.4$ & $174.6 \pm 8.9$ & $<0.0001^{*}$ \\
Weight, kg & $80.1 \pm 16.4$ & $77.2 \pm 15.8$ & $83.9 \pm 16.3$ & $<0.0001^{*}$ \\
BMI & $26.5 \pm 7.8$ & $25.6 \pm 4.3$ & 69 & \\
ASA I & $178(44.3)$ & 109 & 93 & 0.0755 \\
ASA II & $199(49.5)$ & 106 & 13 & \\
ASA III & $25(6.2)$ & 12 & & \\
\hline
\end{tabular}

Values are numbers with percentages in parentheses or means \pm standard deviations. ${ }^{*} \mathrm{p}<0.05$ between the groups with vs. without sedation.

accordance with an observer's assessment of alertness/sedation score of 4-5 [13]. Oxygen was applied in a dosage of $81 / \mathrm{min}$ via an oxygen mask (BS style mask; Intersurgical, Workingham, UK). Respiration was monitored for adequacy with measurement of saturation and semiquantitative $\mathrm{CO}_{2}$ detection. In addition, each patient received a suppository of $100 \mathrm{mg}$ diclofenac (Voltaren 100; Novartis Pharma, Nuremberg, Germany) at the end of surgery to prolong analgesia. After the operation, all patients were directly transferred to the ward until they reached an Aldrete score of 10 [14] without additional monitoring in the recovery room. Patients had no fluid restriction after arrival at the ward. A study nurse recorded the total duration of sensory block, and the time to postoperative mobilization and micturition. The criteria were met at the moment when the patient was able to get up and micturate without any help. The duration of sensory block up to segment S4 was again tested with a long surgical toothless clamp using the technique previously described.

All statistical calculations were made with the SAS System (release 9.01; SAS Institute Inc., Cary, N.C., USA). Differences between the two groups were tested using the two-sample $t$ test, the Mann-Whitney U test, the $\chi^{2}$ test or the Cochran-Armitage trend test, as appropriate. Test results were considered to be statistically significant when $\mathrm{p}<0.05$.

\section{Results}

The performance of the spinal anaesthesia was successful in 498 (of 500) patients (99.6\%). Two patients $(0.4 \%)$ received a general anaesthesia due to adverse puncture conditions and were excluded from the study protocol. In 441 (88.2\%), the performance of the spinal anaesthesia succeeded on the first attempt, in 42 patients after 2 attempts, in 14 patients after 3 attempts and in 3 patients after 4 attempts. During the performance of spinal anaesthesia, 14 patients $(2.8 \%)$ suffered from a decrease in heart frequency and blood pressure that was treated with volume, atropine and vasopressors. The sensory block was adequate for the duration of the surgery for all patients. No other adverse events occurred to any other patients during the course of the study.

With a return of 402 questionnaires, $80.4 \%$ of the patients [143 (35.6\%) females; 259 (64.4\%) males] responded to the survey questions. There were no statistically significant differences between the two groups of responders and non-responders to the survey. Two hundred and twenty-seven of the 402 responding patients (56.5\%) received propofol in a dosage of $58.3 \pm 46.3 \mathrm{mg}$. A higher proportion $(91 / 143 ; 63.6 \%)$ of the responding females compared to $136 / 259(52.5 \%)$ of the responding male patients ( $\mathrm{p}=$ 0.0312 ) required sedation (table 2 ). Patients with sedation were younger $(46.7 \pm 13.8$ vs. $50 \pm 13.8$ years; $\mathrm{p}=0.0171)$ and had a lower body weight $(77.2 \pm 15.8$ vs. $83.9 \pm 16.3$ $\mathrm{kg} ; \mathrm{p}<0.0001)$ as well as a lower body mass index (BMI) $(25.6 \pm 4.3$ vs. $27.5 \pm 5.1 ; \mathrm{p}<0.0001)$. The measured duration of the sensory block was not significantly different for patients with and without additional sedation (table 3). However, there was a significantly longer time to the first mobilization (mean values: 4.8 vs. $4.4 \mathrm{~h} ; \mathrm{p}=0.0194$ ) and first micturition (5.8 vs. $5.4 \mathrm{~h} ; \mathrm{p}=0.0188$ ).

The need for additional sedation was related to a number of indicators in the patients' history and the surgical experience (table 4). The responses indicated similar prior knowledge about spinal anaesthesia regardless of the interoperative use of sedation. Pre-operative anxiety about spinal anaesthesia was higher in patients who required additional sedation $(126 / 227,55.5 \%$ vs. $69 / 175,39.4 \%$; $\mathrm{p}=$ 
Table 3. Properties of the spinal saddle block

\begin{tabular}{|c|c|c|c|c|c|}
\hline Properties of the spinal anaesthesia & $\begin{array}{l}\text { Responding patients } \\
(\mathrm{n}=402)\end{array}$ & $\begin{array}{l}\text { With sedation } \\
(\mathrm{n}=227)\end{array}$ & $\begin{array}{l}\text { Without sedation } \\
(\mathrm{n}=175)\end{array}$ & $\mathrm{p}$ value & Test \\
\hline Total duration of sensory block, $\mathrm{h}$ & $10.0 \pm 7.9(0-24)$ & $9.7 \pm 7.6(0-24)$ & $10.6 \pm 8.4(0-24)$ & 0.8804 & U test \\
\hline Time to first mobilization, $\mathrm{h}$ & $4.6 \pm 2.0(0-24)$ & $4.8 \pm 1.9(0-14)$ & $4.4 \pm 2.1(1-24)$ & $0.0194^{*}$ & U test \\
\hline Time to first micturition, $\mathrm{h}$ & $5.6 \pm 2.7(0-24)$ & $5.8 \pm 2.8(0-24)$ & $5.4 \pm 2.5(1-24)$ & $0.0188^{*}$ & U test \\
\hline
\end{tabular}

Figures are means \pm standard deviations with ranges in parentheses. ${ }^{*} \mathrm{p}<0.05$ between the groups with vs. without sedation.

Table 4. Results of the survey using $\chi^{2}$ tests

\begin{tabular}{|c|c|c|c|}
\hline & & $\begin{array}{l}\text { Rate group } \\
\text { 'with } \\
\text { sedation' } \\
\text { yes:no }\end{array}$ & $\begin{array}{l}\text { Rate group } \\
\text { 'without } \\
\text { sedation' } \\
\text { yes:no }\end{array}$ \\
\hline 1 & General questions & & \\
\hline $\mathrm{a}$ & Knowledge of the 'spinal anaesthesia' & & \\
\hline $\mathrm{b}$ & 'Fears' of spinal anaesthesia* & $126: 101$ & 69:106 \\
\hline c & Influence of the anaesthesiologist* & $188: 38$ & $127: 48$ \\
\hline d & Spinal anaesthesia in patient's & & \\
\hline & history & $73: 154$ & $68: 107$ \\
\hline $\mathrm{e}$ & $\begin{array}{l}\text { Influence of family or acquain- } \\
\text { tances* }\end{array}$ & $63: 163$ & 29:146 \\
\hline 2 & Performance of the spinal anaesthesia & & \\
\hline $\mathrm{a}$ & Perception as 'unpleasing'* & $41: 186$ & $15: 160$ \\
\hline $\mathrm{b}$ & Perception as 'painful'* & 29:197 & $9: 166$ \\
\hline c & Convulsions in the legs & $13: 214$ & $16: 159$ \\
\hline $\mathrm{d}$ & Circulation problems (subjective) & $22: 205$ & $12: 163$ \\
\hline 3 & Perceptions during the operation & & \\
\hline a & 'Pain' & $5: 221$ & $6: 169$ \\
\hline $\mathrm{b}$ & $\begin{array}{l}\text { Strange perceptions in the operation } \\
\text { field }\end{array}$ & $17:$ & $17: 158$ \\
\hline c & Strange sounds/odours & $14: 213$ & $8: 167$ \\
\hline $\mathrm{d}$ & Displeasing mobility & $26: 201$ & $29: 146$ \\
\hline 4 & Side effects & & \\
\hline $\mathrm{a}$ & Headache & $11: 215$ & $10: 165$ \\
\hline $\mathrm{b}$ & Delayed micturition & $25: 202$ & $20: 155$ \\
\hline c & Nausea* & $17: 210$ & $3: 172$ \\
\hline $\mathrm{d}$ & Vomiting & $9: 217$ & $3: 172$ \\
\hline e & Back pain & $24: 202$ & $15: 160$ \\
\hline 5 & Evaluation & & \\
\hline $\mathrm{a}$ & I will choose a saddle block again & 206:19 & $155: 18$ \\
\hline $\mathrm{b}$ & Long-lasting analgesia is important & $200: 26$ & $153: 22$ \\
\hline
\end{tabular}

${ }^{*} \mathrm{p}<0.05$ between the groups with vs. without sedation.
0.0014). Furthermore, these patients indicated a higher rate of influence through either the anaesthesiologist at the pre-anaesthetic interview $(188 / 226,83.2 \%$ vs. $127 / 175$, $72.6 \% ; \mathrm{p}=0.0102)$ or by family and acquaintances $(63 / 226$, $27.9 \%$ vs. $29 / 175,16.6 \% ; \mathrm{p}=0.0076)$. Patients requesting (additional) sedation had a higher rate of pain $(29 / 226$, $12.8 \%$ vs. $9 / 175,5.1 \%$; $=0.0091$ ) and unpleasant sensations during the administration of the spinal anaesthesia (41/227, $18.1 \%$ vs. $15 / 175,8.6 \%$; $=0.0064)$. There was no statistically significant difference in the intra-operative pain experience, unpleasant perceptions, unpleasant sounds or odours and uncomfortable immobility. Sedation also had no effect on patients' perceived postoperative headaches, delayed micturition or back pain. A significantly increased incidence of nausea but not vomiting was related to patients receiving additional sedation (17/227, $7.5 \%$ vs. $3 / 175,1.7 \% ; \mathrm{p}=0.0083)$. Independent of the demanded sedation, most patients $(90.7 \%)$ would choose the spinal saddle block for future anaesthesia again, citing the long-lasting postoperative analgesia as important.

Subgroup analysis was performed for the pre-operative factor 'fear' ('anxiety' and 'prior knowledge of spinal anaesthesia'). Women were significantly more anxious $(80 / 143,55.9 \%$ vs. $115 / 259,44.4 \%$; $p=0.0266)$. Anxiety was also found more frequently in patients who were influenced by the anaesthesiologist to choose spinal anaesthesia $(27 / 86,31.4 \%$ vs. $167 / 315,53.0 \%$; $p=0.0004)$ and in patients without prior experience of spinal anaesthesia (153/261, 58.6\% vs. $42 / 141,29.8 \%$; p < 0.0001$)$. While the experience of the surgical procedure was not significantly different in these patients compared to the total group, the rate of nausea was more than double among patients with anxiety $(14 / 195,7.2 \%$ vs. $6 / 207,2.9 \%$; $p=0.0485)$. Prior knowledge of spinal anaesthesia is associated with an increase in the rate of pain experienced during the administration of the anaesthesia $(36 / 321,11.2 \%$ vs. $2 / 80$, $2.5 \% ; \mathrm{p}=0.0173$ ). 


\section{Discussion}

\section{General Setting and Limits of the Study}

One of the major criticisms of patient satisfaction research relates to methodological issues, including lack of psychometric standards, reliability and validity of surveys, and discriminatory assessment, which reflect the complexity of measuring the multidimensional nature of patient satisfaction [12]. In a review article, Liu and $\mathrm{Wu}$ [12] describe a rate of only $2.1 \%$ randomized controlled trials assessing satisfaction with a validated instrument. Currently, there exists no such validated instrument measuring patients' perceptions before, during and after the performance of spinal anaesthesia with the saddle block technique. The questionnaire used was interdisciplinary, developed in cooperation with physicians and nurses of the disciplines anaesthesiology, coloproctology and medical statistics. We are aware that this study is limited, but nevertheless reflects certain important perioperative aspects.

\section{Sedation}

Sedation has been shown to increase patient satisfaction during regional anaesthesia and is applied at a rate between 12 and 90\% [7]. Propofol is a substance nearest to an ideal agent for sedation during regional anaesthesia because of its favourable pharmacokinetic profile with rapid onset and offset [7]. Even though it is a light sedation, it too involves some risks, such as induction of respiratory depression, haemodynamic instability or uncontrolled movement [7]. In our study, 227/402 (56.47\%) of the patients received additional sedation. No decline of $\mathrm{O}_{2}$ saturation occurred due to additional application of sedatives. The rate of bag valve mask ventilation for additional sedation with propofol in small dosages can lead to the delay described in mobilization and micturition and an increased rate of nausea. The order of 1/500 to $1 / 1,000$ cases [15] did not occur in our study.

The demographic differences in patients with and without sedation can be explained by the significantly higher proportion of women requiring sedation (64 vs. $53 \%)$.

\section{Saddle Block Anaesthesia and Recovery}

Patient demographics were comparable to a similar study evaluating techniques of anaesthesia for anorectal surgery [16]. With a first-attempt rate of 441/500 (88.2\%), the practicability of the spinal anaesthesia was comparable or higher than that in studies of other authors comparing the success rates of experienced anaesthesiologists
(Sprung: 87\%, de Oliveira Filho: 71.4\% [17, 18]). Side effects such as hypotension and bradycardia were lower than in the related literature $[5,19]$, probably due to the low dosage of heavy bupivacaine. The length of sensory block was longer than in a comparable study (600 vs. 255 min) [19], possibly due to the additional use of $100 \mathrm{mg}$ diclofenac at the end of surgery.

Acute urinary retention is a common complication following anorectal surgery with a reported incidence of up to $52 \%$, independent of the type of anaesthesia [20]. In our study, only $11.2 \%$ reported about micturition problems, probably resulting from a restrictive volume management.

\section{Anxiety}

Höhener et al. [7] report an incidence of anxiety of around $50 \%$ before receiving a regional block, which is comparable with $56.5 \%$ in our study. Interestingly, neither prior knowledge of nor prior experience with spinal anaesthesia reduced the rate of additional sedation. Both, however, did decrease the occurrence of anxiety. Anxiety about spinal anaesthesia was less common in patients who had experienced the procedure before (29.8 vs. $58.6 \%)$. Anxiety was higher in women than in men (44.4 vs. $55.9 \%$ ) and those who indicated that they chose spinal anaesthesia at the advice of the anaesthesiologist. The influence of gender on anxiety is controversial in the literature. Some studies found females to be more anxious than males [21], whereas others did not [22]. Anxiety did not have an impact on the patient's experience of the procedure. However, while anxiety was related to a higher rate of nausea, patients who were anxious before the procedure did not experience significantly more pain nor were they less satisfied than patients who were not anxious before the procedure.

\section{Postoperative Nausea and Vomiting}

PONV in spinal anaesthesia is a complex and multifactorial problem not completely understood yet. The incidence of PONV associated with spinal anaesthesia is reported to be as high as $21 \%$, but varies widely [23]. We found an increased rate of nausea among patients receiving additional sedation (7.5 vs. 1.7\%). Recently, van den Bosch et al. showed that high levels of pre-operative anxiety were associated with an increased occurrence of PONV [24]. These data are supported in our study, as increased anxiety was significantly correlated with a doubling of the rate of nausea. Although propofol is known to reduce the incidence of PONV, the anti-emetic effects at sedative doses are controversial $[10,25]$. The rate of 
nausea was too low to allow a separate analysis of these patients.

In general, younger females have a lower body weight and lower BMI than men. This may explain why we found a higher rate of sedation in patients of female gender, younger age, lower body weight and lower BMI. Anxiety can be a reason for sedation and around $50 \%$ of patients are anxious before receiving a regional block [26]. This rate is comparable to $56.5 \%$ patients demanding sedation in our study. In our study, anxiety was higher in women than in men (44.4 vs. 55.9\%). Generally, elderly people are expected to be less anxious, possibly because of their more extended anaesthetic experience $[21,25]$. Neither a former knowledge of spinal anaesthesia nor prior experience with spinal anaesthesia reduced the rate of sedation in our study.

\section{Conclusions}

We found that female gender, younger age, lower body weight and lower BMI were associated with a higher demand rate for sedation during minor anorectal surgery using the saddle block technique. Patients receiving sedation had a delayed mobilization and first micturition after surgery as well as a higher incidence of nausea.

\section{References}

1 Bleday R, Pena JP, Rothenberger DA, Goldberg SM, Buls JG: Symptomatic hemorrhoids: current incidence and complications of operative therapy. Dis Colon Rectum 1992;35:477-481.

2 Gudaityte J, Marchertiene I, Pavalkis D: Anesthesia for ambulatory anorectal surgery. Medicina (Kaunas) 2005;40:101-111.

-3 Li S, Coloma M, White PF, Watcha MF, Chiu JW, Li H, Huber PJ: Comparison of the cost and recovery profile of three anesthetic techniques for ambulatory anorectal surgery. Anesthesiology 2000;93:1225-1230.

-4 Kushwaha R, Hutchings W, Davies C, Rao NG: Randomized clinical trial comparing day-care open haemorrhoidectomy under local versus general anaesthesia. Br J Surg 2008;95:555-563.

5 Korhonen AM: Use of spinal anaesthesia in day surgery. Curr Opin Anaesthesiol 2006; 19:612-616

-6 Wassef MR, Michaels EI, Rangel JM, Tsyrlin AT: Spinal perianal block: a prospective, randomized, double-blind comparison with spinal saddle block. Anesth Analg 2007; 104:1594-1596.

7 Hoehener D, Blumenthal S, Borgeat A: Sedation and regional anaesthesia in the adult patient. Br J Anaesth 2008;100:8-16.

-8 Wilson E, David A, MacKenzie N, Grant IS: Sedation during spinal anaesthesia: comparison of propofol and midazolam. Br J Anaesth 1990;64:48-52.

9 White PF, Negus JB: Sedative infusions during local and regional anaesthesia: a comparison of midazolam and propofol. J Clin Anaesth 1991;3:32-39.
Borgeat A, Wilder-Smith OHG, Saiah M, Rifat K: Subhypnotic doses of propofol possess direct antiemetic properties. Anaesth Analg 1992;74:539-541.

11 Wu CL, Naqibuddin M, Fleisher LA: Measurement of patient satisfaction as an outcome of regional anesthesia and analgesia: a systematic review. Reg Anesth Pain Med 2001;26:196-208.

12 Liu SS, Wu CL: The effect of analgesic technique on postoperative patient-reported outcomes including analgesia: a systemic review. Anesth Analg 2007;105:789-808.

13 Chernik DA, Gillings D, Laine H, Hendler J, Silver JM, Davidson AB, Schwam EM, Siegel JL: Validity and reliability of the Observer's Assessment of Alertness/Sedation Scale: study with intravenous midazolam. J Clin Psychopharmacol 1990;10:244-251.

14 Aldrete JA, Kroulik D: A postanesthetic recovery score. Anesth Analg 1970;49:924934.

15 Trummel J: Sedation for gastrointestinal endoscopy: the changing landscape. Curr Opin Anaesthesiol 2007;20:359-364.

-16 Read TE, Henry SE, Hovis RM, Fleshman JW, Birnbaum EH, Caushaj PF, Kodner IJ: Prospective evaluation of anaesthetic technique for anorectal surgery. Dis Colon Rectum 2002;45:1553-1560.

17 Sprung J, Bourke DL, Grass J, Hammel J, Mascha E, Thomas P, Tubin I: Predicting the difficult neuraxial block: a prospective study. Anesth Analg 1999;89:384-389.

18 de Oliveiro Filho GR, Gomes HP, da Fonesca MHZ, Hoffman JC: Predictors of successful neuraxial block: a prospective study. J Eur Anaesthesiol 2002;19:447-451.
19 Whiteside JB, Burke D, Wildsmith JAW: Comparison of ropivacaine $0.5 \%$ (in glucose $5 \%$ ) with bupivacaine $0.5 \%$ (in glucose $8 \%$ ) for spinal anaesthesia for elective surgery. $\mathrm{Br}$ J Anaesth 2003;90:304-308.

20 Prasad ML, Abcarian H: Urinary retention following operations for benign anorectal diseases. Dis Colon Rectum 1978;21:490492.

21 Badner NH, Nielson WR, Munk S, Kwiatkowska C, Gelb AW: Preoperative anxiety: detection and contributing factors. Can J Anaesth 1990;37:444-447.

22 Kindler $\mathrm{CH}, \mathrm{Harms} \mathrm{C}$, Amsler F, Ihde-Scholl T, Scheidegger D: The visual analog scale allows effective measurement of preoperative anxiety and detection of patients' anesthetic concerns. Anesth Analg 2000;90:706-712.

23 Borgeat A, Ekatodramis G, Schenker CA: Postoperative nausea and vomiting in regional anaesthesia. Anaesthesiology 2003; 98:530-547.

24 Van den Bosch JE, Moons KG, Bonsel GJ, Kalkman CJ: Does measurement of preoperative anxiety have added value for predicting postoperative nausea and vomiting? Anaesth Analg 2005;100:1525-1532.

25 Hasen KV, Samartzis D, Casas LA, Mustoe TA: An outcome study comparing intravenous sedation with midazolam/fentanyl (conscious sedation) versus propofol infusion (deep sedation) for aesthetic surgery. Plast Reconstr Surg 2003;112:1683-1689.

26 Villeret I, Laffon M, Ferrandiere M, Delerue D, Fusciardi J: Which propofol target concentration for ASA III elderly patients for conscious sedation combined with regional anaesthesia? Ann Fr Anesth Reanim 2003; 22:196-201. 